\title{
Neuropharmacological Profile of Fractions of Actaea acuminata H. Hara Roots
}

\section{DEEPAK KUMAR AND SURESH KUMAR*}

Department of Pharmaceutical Sciences and Drug Research, Punjabi University, Patiala-147 002, Punjab, India

\section{*Email: thakur_pu@yahoo.com}

Received: Dec. 01, 2017 | Revised: Feb. 02, 2018 | Accepted: Feb. 19, 2018

Published online: May 02, 2018

The Author(s) 2018. This article is published with open access at www.chitkara.edu.in/publications

\begin{abstract}
The methanol extract of Actaea acuminata roots have been previously reported to exhibit significant antianxiety, anticonvulsant and antidepressant activities. In present study fractionation of crude bioactive methanol extract was carried out using different solvents employing standard procedure. Various fractions were evaluated for antianxiety, anticonvulsant and antidepressant activities using elevated plus maze model (EPM), maximal electroshock-induced convulsions model (MES) and forced / despair swim test (FST) respectively. Successive partitioning of bioactive methanol extract was done with ethyl acetate and 1-butanol. The ethyl acetate fraction (EAF; 100 $\mathrm{mg} / \mathrm{kg}), 1$-butanol fraction $(\mathrm{BF} ; 25 \mathrm{mg} / \mathrm{kg}$ ) and remaining methanol extract (RME; $70 \mathrm{mg} / \mathrm{kg}$ ) were subjected to neuropharmacological activities. The EAF significantly enhanced entries and average time spent in open arms; significantly decreased duration of MES-induced tonic extension phase and significantly decreased duration of immobility time of rats in comparison to control. BF and RME did not exhibit any neuropharmacological activity. Qualitative chemical tests confirmed presence of alkaloids and polyphenols in EAF. It is finally concluded that alkaloids and/or polyphenols are bioactive constituents of A. acuminata which are responsible for neuropharmacological activities.
\end{abstract}

Keyword: Actaea acuminata, Alkaloids, Flavonoids, Himalayan Baneberry.

\section{INTRODUCTION}

Journal of Pharmaceutical

Technology, Research and Management

Vol-6, No-1,

May 2018 pp. 1-8

increase to about $15 \%$ by 2020 (Prince et al., 2007; Mcdaid et al., 2008). The 
Kumar, D

Kumar, S

mental illness is more prevalent among US adults and estimated to be $4.5 \%$ (NIH, 2008). As per data of 2010/11, more than 1.25 million adults utilized NHS services for critical mental health problems. It has been reported that a professional has treated more than $25 \%$ of college students suffering from mental health condition in a year (NAMI, 2013). The annual cost of mental illness has been estimated to be US\$79 billion in the US, and approximately US $\$ 63$ billion results from the loss of productivity (Rockville, 1999).

A large number of synthetic drugs are available in market to manage neuropsychiatric disorders but having drawback of severe side effects. Therefore, natural resources seem viable alternative to search for safer and effective drugs. A thorough survey of literature reveals that large numbers of plants are used in the treatment of CNS disorders. Systematic and scientifically structured research is required on most of these plants. Among such plants, Actaea acuminata (Wall. ex Royle) H. Hara, commonly known as Himalayan Baneberry (family - Ranunculaceae) was shortlisted for present investigation.

A. acuminata has been recorded in traditional texts in the treatment of nervous disorders, scrofula, rheumatic fever, inflammation, rheumatism, cough and constipation (Anonymous, 1948; Chopra et al., 1956; Kirtikar \& Basu, 1975; Khare, 2007).

The methanol extract of the plant has been investigated scientifically for neuropharmacological activities (Biswas et al., 2017). The methanol extract exhibits significant antianxiety, anticonvulsant and antidepressant activities. In continuation to above finding, it was envisaged to fractionate bioactive methanol extract and to evaluate antianxiety, anticonvulsant and antidepressant activities of various fractions using well established models.

\section{MATERIALS AND METHODS}

\subsection{Collection and Identification Number of Plant Material}

K. R. Indo German American Trading Company, Kurukshetra (Haryana), India supplied A. acuminata roots in August, 2015. The identification of the plant was confirmed through Dr. Avneet Pal Singh, Assistant Professor, Department of Botany, Punjabi University, Patiala, India (Reference No. SPL-110/Bot, dated 15-09-2015).

\subsection{Solvents}

Ethyl acetate, methanol and 1-butanol (E Merck, New Delhi, India) of LR grade were used for preparing methanol extract and various fractions of $A$. acuminata roots. 


\subsection{Fractionation of Methanol Extract (ME)}

The methanol extract was prepared using standard procedure (Biswas et al., 2017). The suspension of ME (100 g) of plant material was prepared in water $(500 \mathrm{ml})$. It was then taken in a round bottom flask. The extract was then subjected to successive partitioning with ethyl acetate $(10 \times 250 \mathrm{ml})$ and 1-butanol $(10 \times 250 \mathrm{ml})$. The separated layers of each solvent were collected and pooled. All fractions were concentrated under reduced pressure to get ethyl acetate fraction (EAF), 1-butanol fraction (BF) and remaining methanol extract (RME). The various fractions were subjected to phytochemical screeing for presence of different groups of phytoconstituents (Farnsworth, 1966).

\subsection{Animal Experimentation}

S D rats of body weight 200-300 g, either sex, purchased from the Institute of Microbial Technology, Chandigarh, India were used for present investigations. Normal laboratory pellet diet and water ad libitum were provided to animals. The approval of animal studies from Institutional Animal Ethics Committee of Punjabi University, Patiala was obtained (Registration number - 107/1999/ CPCSEA, dated 28/04/1999; Approval number - 107/GO/ReBi/S/99/ CPCSEA/2017-04, dated 27-02-2017).

\subsection{Neuropharmacological Activities}

Antianxiety, anticonvulsant and antidepressant activities of various fractions were evaluated using elevated plus maze model (EPM; Designed from local market Patiala as per standard specification), maximal electroshock-induced convulsions model (MES; Gupta Scientific Store, Ambala) and forced swim test (FST; Gupta Scientific Store, Ambala) respectively (Biswas et al., 2017). Diazepam (Triko Pharmaceuticals, Haryana, India; $2 \mathrm{mg} / \mathrm{kg}$, p.o.), phenytoin (Epsolin injections ${ }^{\circledR}$, Zydus Neurosciences, Ahmedabad; $100 \mathrm{mg} / \mathrm{kg}$, i.p.) and imipramine Diazepam (Triko Pharmaceuticals, Haryana, India; $5 \mathrm{mg} / \mathrm{kg}$, p.o.) were used as standard antianxiety, anticonvulsant and antidepressant drugs respectively. The $2 \%$ mixture of Tween 80 and distilled water was used as vehicle for the preparation of test doses of various fractions.

\subsection{Experimental Protocol}

Experimental protocol comprising 5 groups of rats (for each activity studies) was designed to assess antianxiety, anticonvulsant and antidepressant activities of various fractions of $\mathrm{ME}$ of A. acuminata roots. The animals of control group were administered vehicle $(0.25 \mathrm{ml}$, p.o. $)$, where as animals of standard group
Neuropharmacological Profile of Fractions of Actaea acuminata $\mathrm{H}$. Hara

Roots

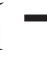

(1)


Kumar, D

Kumar, S

received respective standard drug. $\mathrm{EAF}$ (100 mg/kg, p.o.), $\mathrm{BF}$ (25 mg/kg, p.o.) and RME (70 mg/kg, p.o.) were served as test groups.

\subsection{Statistics}

The observations of results were compiled in to data, which were presented as mean \pm standard deviation (SD). One way analysis of variance (ANOVA) followed by Student Newman Keul's test was applied to compare control, standard and test groups (Scheffer, 1980).

\section{RESULT}

The percentage yields of EAF, BF and RME were 52.63, 11.13 and 35.26\%, respectively, in relation to $\mathrm{ME}$. Qualitative chemical tests for identification of various phytoconstituents confirmed the presence of alkaloids, phenolic compounds, steroids and flavonoids in EAF; tannins in BF and carbohydrates, proteins in RME. Various fractions were subjected to antianxiety, anticonvulsant and antidepressant activities in rats using well established models. The test doses were selected on the basis of percentage yields of fractions with respect to bioactive ME.

The antianxiety activity was screened after administration of EAF (100 $\mathrm{mg} / \mathrm{kg}$, p.o.), BF (25 mg/kg, p.o.), RME (70 mg/kg, p.o.), diazepam (2 mg/ $\mathrm{kg}$, p.o.) and the control (vehicle, p.o.) of $A$. acuminata roots in rats using EPM model. The results of antianxiety activity such as number of entries and average time spent in open arms have been presented in Table 1. Amongst various fractions tested, only EAF produced significant antianxiety effect as it caused significant increase in open arm entries and time spent by rats in comparison to control. Antianxiety activity observed in EAF was statistically

Table 1: Antianxiety activity of various fractions of ME of $A$. acuminata roots using EPM model.

\begin{tabular}{cccc}
\hline Treatment & Dose (mg/kg) & $\begin{array}{c}\text { Number of entries in } \\
\text { open arms }\end{array}$ & $\begin{array}{c}\text { Time spent in open arms } \\
\text { (sec) }\end{array}$ \\
\hline Control & Vehicle & $3.67 \pm 0.51^{\mathrm{a}}$ & $5.67 \pm 0.51^{\mathrm{a}}$ \\
Diazepam & 2 & $9.17 \pm 0.75^{*}$ & $18.00 \pm 0.63^{*}$ \\
EAF & $\mathbf{1 0 0}$ & $\mathbf{9 . 0 0} \pm \mathbf{0 . 8 9 ^ { * }}$ & $\mathbf{1 7 . 8 3} \pm \mathbf{0 . 7 5 ^ { * }}$ \\
BF & 25 & $4.67 \pm 0.52^{\mathrm{a}}$ & $6.50 \pm 0.54^{\mathrm{a}}$ \\
RME & 70 & $3.50 \pm 0.54^{\mathrm{a}}$ & $5.33 \pm 0.51^{\mathrm{a}}$ \\
\hline
\end{tabular}

$\mathrm{n}=6$; The data is expressed as Mean \pm S.D.; $* P<0.05$ vs Control; ${ }^{\text {a }} P<0.05$ vs Diazepam; one way ANOVA followed by Student-Newman-Keul's test. 
not different to the standard drug. BF and RME did not exhibit antianxiety activity at the tested doses. These observations inferred that only EAF contains major constituents which are responsible for CNS activities of the plant.

The EAF (100 mg/kg, p.o.), BF (25 mg/kg, p.o.), RME (70 mg/kg, p.o.), phenytoin $(100 \mathrm{mg} / \mathrm{kg}$, i.p.) and the control (vehicle, p.o.) of A. acuminata roots were subjected to anticonvulsant activity in rats using MES test. The results of anticonvulsant activity parameters such as time spent in extensor phase in the rats and percentage protection of animals have been presented in Table 2. Amongst various fractions tested, only EAF caused a significant decrease in duration of MES-induced tonic extension phase in the rats, thus, exhibited anticonvulsant activity. BF and RME did not exhibit anticonvulsant activity.

Table 2: Anticonvulsant activity of various fractions of ME of A. acuminata roots using MES test.

\begin{tabular}{cccc}
\hline Treatment & Dose $(\mathbf{m g} / \mathbf{k g})$ & $\begin{array}{c}\text { Time spent in extensor } \\
\text { phase }(\mathbf{s e c})\end{array}$ & $\begin{array}{c}\text { \% Protection of } \\
\text { animals }\end{array}$ \\
\hline Control & Vehicle & $11.50 \pm 1.04^{\mathrm{a}}$ & 33.3 \\
Phenytoin & 100 & $1.33 \pm 0.51^{*}$ & 100.0 \\
EAF & $\mathbf{1 0 0}$ & $\mathbf{1 . 5 0} \pm \mathbf{0 . 8 3}^{*}$ & $\mathbf{1 0 0 . 0}$ \\
BF & 25 & $9.50 \pm 1.15^{\mathrm{a}}$ & 33.3 \\
RME & 70 & $11.83 \pm 0.75^{\mathrm{a}}$ & 33.3 \\
\hline
\end{tabular}

$n=6$; The data is expressed as Mean \pm S.D.; $* P<0.05$ vs Control; ${ }^{a} P<0.05$ vs Phenytoin; one way ANOVA followed by Student-Newman-Keul's test.

The EAF (100 mg/kg, p.o.), BF (25 mg/kg, p.o.), RME (70 mg/kg, p.o.), imipramine $(5 \mathrm{mg} / \mathrm{kg}$, p.o. ) and the control (vehicle, p.o.) of A. acuminata roots were subjected to antidepressant activity in rats using FST. The results of antidepressant activity such as mean immobility time of the rats have been presented in Table 3. Amongst various fractions tested, only EAF caused a significant decrease in duration of immobility time of the rats in comparison to control and statistically not different to the standard drug. BF and RME did not exhibit anticonvulsant activity.

\section{DISCUSSION}

The evaluation of antianxiety activity of $A$. acuminata roots fractions was done using EPM. In this model when animals are exposed to an elevated and open maze, results in approach-avoidance conflict in animals. Significant decrease
Neuropharmacological Profile of Fractions of Actaea acuminata $\mathrm{H}$. Hara

Roots

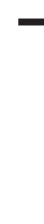


Kumar, D

Kumar, S
Table 3: Antidepressant activity of various fractions of ME of A. acuminata roots using FST.

\begin{tabular}{ccc}
\hline Treatment & Dose $(\mathbf{m g} / \mathbf{k g})$ & Immobility time (sec) \\
\hline Control & Vehicle & $158.17 \pm 8.37^{\mathrm{a}}$ \\
Imipramine & 5 & $42.33 \pm 2.16^{*}$ \\
EAF & $\mathbf{1 0 0}$ & $\mathbf{4 3 . 3 3} \pm \mathbf{3 . 8 3}$ \\
BF & 25 & $150.33 \pm 6.05^{\mathrm{a}}$ \\
RME & 70 & $153.83 \pm 6.49^{\mathrm{a}}$ \\
\hline
\end{tabular}

$\mathrm{n}=6$; The data is expressed as Mean \pm S.D.; $* P<0.05$ vs Control; ${ }^{a} P<0.05$ vs Imipramine; one way ANOVA followed by Student-Newman-Keul's test.

in time spent and number of entries in open arms observed infers anxiety in the animals (Belzung \& Griebel, 2001).

Various fractions of $A$. acuminata roots were screened for anticonvulsant activity using widely employed model, i.e., MES. The model is based on the observation of duration of the seizures which was induced by maximal electroshock in mice with the help of electroconvulsiometer by passing current using ear clip electrodes. The anticonvulsant activity of test drugs in animals was assessed based on following parameter (a) time spent by animals in extensor phase and (b) percentage protection against MES induced convulsive death in mice. The anticonvulsant activity in the animals is confirmed by decrease in the duration of extensor phase and maximum percentage of the protection against MES induced convulsive deaths in mice (Swinyard et al., 1952).

Forced swimming test was employed to screen various fractions of A. acuminata roots for antidepressant activity. In this model, characteristic behaviour of immobility is observed in mice when they are forced to swim in inescapable specified area. Depression in mice of control group is inferred from higher mean time spent in the immobile state (Weiss et al., 1981).

\section{CONCLUSION}

The previously reported bioactive methanol extract was fractionated in order to get semi-purified fractions. The fractions were screened for antianxiety, antidepressant and anticonvulsant activities employing widely used models. Amongst various fractions tested, only EAF exhibited significant antianxiety, anticonvulsant and antidepressant activities. Phytochemical screening showed presence of phenolic compounds, flavonoids and alkaloids as bioactive constituents. Finally, it is concluded that neuropharmacological activities of A. acuminata are attributed due to these bioactive constituents. 


\section{ACKNOWLEDGEMENT}

The Department of Science and Technology (DST), New Delhi has provided financial assistance to Dr Suresh Kumar to carry out the present research work. This financial support by the DST is duly acknowledged.
Neuropharmacological Profile of Fractions of Actaea acuminata $\mathrm{H}$. Hara Roots

\section{DECLARATION OF INTEREST}

The authors report no declaration of interest.

\section{REFERENCES}

[1] Anonymous. (1948). A Dictionary of Indian Raw Materials and Industrial Products, in the Wealth of India. Council of Scientific and Industrial Research, New Delhi, India, 314.

[2] Belzung, C. \& Griebel, G. (2001). Measuring normal and pathological anxiety like behaviour in mice: A review. Brain Research Reviews, 125(1-2), 141-149. https://doi.org/10.1016/S0166-4328(01)00291-1

[3] Biswas, D., Kumar, D.\& Kumar, S. (2017). Neuropharmacological investigations on Actaea acuminata H. Hara roots. Indian Journal of Experimental Biology, 55(1), 27-35.

[4] Chopra, R.N., Nayar, S.L. \& Chopra, I.C. (1956). Actaea acuminata, in Glossary of Indian Medicinal Plants. Council of Scientific and Industrial Research, New Delhi, India, 7.

[5] Farnsworth, N.R. (1966). Biological and phytochemical screening of plants. Journal of Pharmaceutical Sciences, 55(3), 225-276. https://doi.org/10.1002/jps.2600550302

[6] Khare, C.P. (2007). Actaea spicata Linn., in Indian Medicinal Plants: An Illustrated Dictionary. Spinger Science and Business Media, New York, USA, 17.

[7] Kirtikar, K.R. \& Basu, B.D. (1975). Actaea spicata Linn., in Indian Medicinal Plants. International Book Distributors, Allahabad, India, 51.

[8] Mcdaid, D., Knapp, M. \& Raja, S. (2008). Barriers in the mind: Promoting an economic case for mental health in low and middle income countries. World Psychiatry, 7(2), 79-86. https://doi.org/10.1002/j.2051-5545.2008.tb00160.x

[9] NAMI. (2013). Mental Health Issues are Prevalent on College Campuses. National Alliance on Mental Illness. Available from:

https://www .nami.org/Press-Media/In-The-News/2017/How-Parents-CanIdentify-Mental-Health-Problems-in. Accessed on July, 2017.

[10] NIH. (2008). NIH Consensus Development Conference Statement on Management of Mental Heath. National Institutes of Health. Available online: https://medlineplus.gov/ mentaldisorders.html. Accessed on July, 2017. 
Kumar, D

Kumar, S
[11] Prince, M., Patel, V., Saxena, S., Maj, M., Maselko, J., Phillips, M.R.\& Rahman, A. (2007). No health without mental health. The lancet, 370(9590), 859-877. https://doi.org/10.1016/S0140-6736(07)61238-0

[12] Rockville. (1999). U.S. Department of Health and Human Services. Substance Abuse and Mental Health Services Administration. Center for Mental Health Services, Maryland, 411.

[13] Scheffer, W.C. (1980). Statistics for the Biological Sciences. Addison-Wesley Publishing Company, Philippines, 121-141.

[14] Swinyard, E.A., Brown, W.C. \& Goodman, L.S. (1952). Comparative assays of antiepileptic drugs in mice and rats. Journal of Pharmacology and Experimental Therapeutics, 106(3), 319-330.

[15] Weiss, J.M., Goodman, P.A., Losito, G.O., Corrigan, S., Carris, J.M. \& Bailey, W.H. (1981). Behavioural depression produced by uncontrollable stressor: Relationship to norepinephrine, dopamine and serotonin levels in various regions of rat brain. Brain Research Reviews, 3(2), 167-205. https://doi.org/10.1016/0165-0173(81)90005-9 